\title{
Introduction to special issue: Skepticism and Epistemic Angst
}

\author{
J. Adam Carter ${ }^{1}$. Guillaume Dechauffour ${ }^{2}$. Grégoire Lefftz ${ }^{3}$ \\ Published online: 23 June 2021 \\ (c) The Author(s), under exclusive licence to Springer Nature B.V. 2021
}

The special issue's theme, Skepticism and Epistemic Angst, is centered around some of the latest and most provocative recent thinking by internationally renowned epistemologists on the topic of epistemological skepticism—roughly, the problem that consists in vindicating our knowledge of the external world in the face of radical skeptical challenges.

Arguably the most influential recent anti-skeptical strategy has been advanced by Duncan Pritchard in his 2016 monograph Epistemic Angst: The Groundlessness of Our Believing. In this book, Pritchard maintains that the skeptical problem is actually two logically distinct paradoxes in disguise-one formulation of which turns on the 'closure' principle, and another distinct formulation that turns on the 'underdetermination' principle. ${ }^{1}$ Pritchard maintains further that what might be a perfectly adequate solution to one of these formulations of the paradox need not thereby be an adequate solution to the other formulation. His attempt to resolve these logically distinct skeptical paradoxes-what he terms his biscopic solution-draws from material from Wittgenstein's On Certainty ${ }^{2}$ in order to deal with the closure-based

\footnotetext{
${ }^{1}$ For a previous discussion of closure- and underdetermination-based skeptical arguments, see Pritchard (2005).

${ }^{2}$ See, e.g., Wittgenstein (1969).

J. Adam Carter

adam.carter@glasgow.ac.uk

Guillaume Dechauffour

guillaume.dechauffour@sorbonne-universite.fr

Grégoire Lefftz

gregoire.lefftz@hotmail.com

1 University of Glasgow, Glasgow, UK

2 Sorbonne Université, Paris, France

3 Independent scholar, Orléans, France
} 
problem, and McDowell (1994) ${ }^{3}$ in order to deal with the underdetermination-based problem. ${ }^{4}$

Several of the papers in this special issue respond to Pritchard's new skeptical solution-most of these focus in some way on the Wittgensteinian 'hinge' component of his approach - and they were the basis of a recent high-profile international workshop (January 2017), held at Paris-Sorbonne University. The special issue, however, was opened also to other contributions, some of which engage with Epistemic Angst directly, others which focus more generally on related skeptical themes.

Annalisa Coliva's contribution, "Strange Bedfellows. On Pritchard's Disjunctivist Hinge Epistemology" takes issue with Pritchard's attempt to combine Wittgensteinian hinge epistemology with epistemological disjunctivism. Points of substantive focus for Coliva include (i) the proposed treatment of the closure principle in Epistemic Angst in relation to entailments containing hinges; (ii) Pritchard's treatment of the underdetermination-based skeptical paradox; (iii) and, relatedly, his appeal to a disjunctivist strategy in order to resolve this paradox.

The relationship between hinges and closure is also taken up by Xiaoxing Zhang, in his paper "Closure, Deduction and Hinge Commitments." However, for Zhang, the key critical point raised in connection with hinges and closure centers around Pritchard's stance on the nature of hinges themselves - for which Pritchard defends a 'non-belief' reading, viz., one that draws attention to important ways in which beliefs and hinges differ.

Mona Simion, Johanna Schnurr, and Emma C. Gordon's contribution "Epistemic Norms, Closure, and No-Belief Hinge Epistemology" also picks up on this theme. While Simion et al. take the relationship between a no-belief hinge epistemology and closure as a focal point, they also expand their discussion to assess the prospects for a no-belief reading of hinges more generally.

Two additional papers in the special issue are similarly concerned with themes that touch upon both closure and hinges. Matthew Jope's central aim in "Closure, Credence and Rationality: A Problem for Non-Belief Hinge Epistemology" is to show that Pritchard's argument for the claim that there can be no rational basis to believe our anti-sceptical hinge commitments relies upon an implicit assumption about rational support that, suitably understood, leads to irrational doxastic attitudes.

Ram Neta's paper, "An Evidentalist Account of Hinges," takes a different tack concerning hinges and closure. Neta maintains that the idea-often attributed to Wittgenstein - that our commitment to the trustworthiness of our evidence is not itself evidentially grounded is not charitable as a reading of Wittgenstein, and that an alternative reading of Wittgenstein's epistemology offers better traction against the closure-based skeptical puzzle; to this end, Neta defends a positive evidentialist account of hinges, one with reference to which we can countenance ourselves as knowing the denial of radical skeptical hypotheses.

\footnotetext{
3 Though McDowell is an inspiration for epistemological disjunctivism of the sort that Pritchard avails himself to in Epistemic Angst, the specifics of the epistemological disjunctivist strategy are really more closely aligned with Pritchard's own (2012) version of the view, which is distinct as an epistemological thesis from the more general kind of disjunctivism generally attributed to McDowell.

4 For a precis of Epistemic Angst, see Pritchard (2016).
} 
John Greco's paper "Hinge Epistemology and the Prospects for a Unified Theory of Knowledge" connects hinge epistemology with virtue epistemology, and in particular, with virtue reliabilism. ${ }^{5}$ His first key move is to link hinge propositions with "procedural knowledge," by thinking of the former in terms of the latter; from here Greco maintains that thinking of hinge commitments as a kind of procedural knowledge allows a unified virtue-theoretic treatment of the generation of knowledge, the transmission of knowledge, and Wittgensteinian "hinge knowledge."

Marion Vorms and Ulrike Hahn's co-authored contribution, "In the Space of Reasonable Doubt," engages with a longstanding skeptical theme in the judicial domain-which is that of reasonable doubt. After challenging a decision-theoretic conception of reasonable doubt, Vorms and Hahn maintain that the lens of reasonable doubt sheds light on aspects of belief dynamics, as well as of the nature of epistemic attitudes, which are often obscured by belief-centered approaches. A wider lesson drawn is that studying the various facets of doubt rather than focusing on what can be believed, enables one to do justice to the richness and diversity of the mental states in play.

Finally, Duncan Pritchard rounds out the special issue, with a contribution that both (i) provides an overview of some of the key themes and arguments from Epistemic Angst; and then (ii) replies to various criticism raised to his project that featured in this special issue.

We believe that these eight articles in the special issue-each representative in its own way of the special issue's theme-signal (collectively) the importance of skepticism and epistemic angst in epistemology, and especially hinge epistemology as an anti-skeptical strategy, and we hope they will serve as a basis for future work in these areas.

\section{References}

Greco, J. (2010). Achieving knowledge: A virtue-theoretic account of epistemic normativity. Cambridge University Press.

McDowell, J. (1994). Mind and world: With a new introduction. Harvard University Press.

Pritchard, D. (2005). Epistemic luck. Clarendon Press.

Pritchard, D. (2012). Epistemological disjunctivism. Oxford University Press.

Pritchard, D. (2016). Epistemic angst: Radical skepticism and the groundlessness of our believing. Princeton University Press.

Wittgenstein, L., Anscombe, G. E. M., von Wright, G. H., Paul, D., \& Anscombe, G. E. M. (1969). On certainty (Vol. 174). Blackwell.

Publisher's Note Springer Nature remains neutral with regard to jurisdictional claims in published maps and institutional affiliations.

\footnotetext{
${ }^{5}$ See, e.g., Greco (2010) for an example of this position.
} 